\title{
O ensino da tática e da técnica no futebol: concepção de treinadores das categorias de base La enseñanza de táctica y técnica en el fútbol: conocimientos de entrenadores de categorías de formación Teaching tactics and technique in football: conceptions of basic categories coaches *Otávio Bettega, *Alcides Scaglia, **Juarez Nascimento, ***Sérgio Ibáñez, *Larissa Galatti *Universidade Estadual de Campinas (Brasil), ** Universidade Federal de Santa Catarina (Brasil), ***Universidad de Extremadura (España)
}

Resumo. O desenvolvimento de conteúdos tático-técnicos no processo de ensino-treino do futebol é atribuição fundamental do treinador, buscando coordenar e orientar possíveis ações de jogo dos atletas. Assim, o artigo objetiva analisar a concepção de treinadores das categorias de base de um clube de elite do futebol brasileiro sobre aspectos técnicos e táticos do plano, do treino e do jogo. Participaram de entrevista semiestruturada oito treinadores do sub-10 ao sub-17, sendo o tratamento das informações realizado por meio da análise de conteúdo. Nas temáticas de plano e treino, sete treinadores investigados visualizam e desenvolvem a técnica de forma descontextualizada da tática. Contraditoriamente, na temática referente ao jogo os treinadores avaliam o contexto tático do jogo, não atribuindo relevância para o aspecto técnico. Portanto, torna-se relevante o treinador ter coerência e compreender o processo de planejar, treinar e jogar de forma complementar, contextualizando o desenvolvimento da técnica e da tática. Palavras-Chaves: Futebol; Treinador; Categorias de Base; Formação de jogadores; Tática e Técnica.

Resumen. El desarrollo de los contenidos táctico-técnicos en el proceso de enseñanza-entrenamiento del fútbol configura tarea central del entrenador, objetivando coordinar y orientar posibles acciones de juego de sus deportistas. Como un paisaje complejo que incluye constantemente el afrontamiento a los problemas tácticos-técnicos. En este sentido, se hace necesario que el entrenador comprenda estos problemas para que pueda guiar acciones tomadas por los jugadores. Así, esta investigación tiene como objetivo analizar la concepción de los entrenadores de las categorías inferiores de un club de elite del fútbol brasileño en los aspectos técnicos y tácticos del plan, el entrenamiento y el partido. Participaron de una entrevista semiestructura ocho entrenadores (del sub-10 al sub-17), y el tratamiento de datos realizados por el análisis de contenido. En las categorías plan y entrenamiento predominó la percepción y enseñanza de la técnica descontextualizada de la táctica. Contradictoriamente, en la categoría juego los entrenadores evalúan el contexto táctico del juego, sin valorar al aspecto técnico. Por lo tanto, se hace importante para el entrenador tener consistencia y comprender el proceso de planificación, entrenamiento y el juego de una manera complementaria, contextualizando el desarrollo de la técnica y la táctica. Palabras clave: Fútbol; Entrenador; Categorías de Formación; Formación de Jugadores; Táctica y Técnica.

\begin{abstract}
Coaching tactical-technical competences is a central task for soccer coaches, as it aims to better organize athletes' actions during games. In this sense, it becomes necessary for coaches to understand such problems, to stimulate players' better decision-making processes. Therefore, this paper aims to analyze youth category soccer coaches' conceptions about tactical and technical issues in planning, training, and competition, in an elite Brazilian soccer club. Semi-structured interviews were conducted with eight coaches (from U-10 to U-17); data analysis was performed through content analysis. In planning and training topics, most of the coaches view and develop technical training separated form tactical aspects. Contradictorily, in the theme referring to competition coaches evaluated the tactical context of games, whereas they considered technical aspects as non-relevant. Therefore, being coherent and understanding the processes of planning, coaching and playing in a complementary way, contextualizing the development of tactical and technical, becomes essential for any youth category coach.
\end{abstract}

Keywords: Soccer; Coach; Youth Sport; Players Education; Tactical and Technical.

\section{Introdução}

Treinar crianças ejovens no esporterepresentauma tarefa complexa, que deve ser compreendida e desenvolvida em longo prazo. Santos et al (2016) destacam a importância do papel do treinador de jovens e que os estudos nessa linha vêm aumentando. No futebol, o treinador de categorias de base necessita planejar, aplicar e avaliar os cenários de treino ejogo (competição), de maneira que seu comportamento expresse sua concepção, sendo coerente com o que desenvolve e o que cobra de seus jogadores (Santos, Lopes, Rodrigues, 2016). Nessa perspectiva, Riola e D’Isanto (2015) evidenciam a periodização dos conteúdos desenvolvidos no futebol e sua contextualização a partir dos aspectos físicos, psicológicos e tático-técnicos.

No caso dos conteúdos tático-técnicos, o treinador precisa considerar a compreensão dos jogadores sobre o jogo, bem como a forma como interagem no jogo. Os treinadores devem conceber o processo de ensino-treino do futebol como um sistema não linear, dependente das interações internas e externas ao jogo, sendo que a construção das atividades não deve centrar-se na aplicação de tarefas fechadas e com respostas prontas, mas na busca constante por diferentes caminhos (Lee, Chow, Komar, Tan \& Button, 2014). Chow, Davids, Button e Renshaw (2013) ressaltam a necessidade da concepção do treinador e sua abordagem pedagógica ser dinâmica enão linear, atribuindo fatores como: a) busca por soluções com base na percepção motora, restrições estruturais e interação entre indivíduo e ambiente; b) consideração da variabilidade na aquisição de novos padrões de movimento; e c) compreensão das instruções para interpretar corretamente as diferentes

Fecha recepción: 16-02-17. Fecha de aceptación: 14-05-17 Otávio Bettega otavio.b.bettega@gmail.com possibilidades de resolução dos problemas.

O processo de formação tático-técnico de jovens jogadores no futebol deve configurar-se na diversificação das formas de jogar, estimulando os jogadores na procura de soluções para os diferentes problemas do jogo enão direcionando a repetição de exercícios com ações erespostas preestabelecidas (Bettega, Scaglia, Morato \& Galatti, 2015). Isso posto, enfatiza-se que a formação do jogador de futebol deve repousar em práticas com elevada variabilidade de constrangimentos, gerando constantes adaptações, possibilidades de descoberta, auto aprendizado e contextualizando a técnica com a tática (Araújo, Fonseca, Davids, Garganta, Volossovicth, Brandão \& Krebs, 2010).

Apesar da literatura da área recomendar a necessária contextualização tática do treino técnico nas modalidades coletivas e, em especial, no futebol, poucas investigações têm se concentrado sobre como os treinadores estruturam esse processo em clubes formadores de jovens jogadores. Todavia, em outras modalidades e contextos, já se observam estudos nessa linha, como no vitorioso basquetebol espanhol (Cañadas, Parejo, Ibáñez, Garcia \& Feu, 2009; Cañadas, Ibáñez, Leite, 2015). Dada a carência observada em nosso contexto, o objetivo do estudo foi analisar a concepção de treinadores das categorias de base de um clube de elite do futebol brasileiro sobre os aspectos técnicos e táticos ao planejar as sessões de treino, ao comandar os treinamentos e durante partidas oficiais (competição).

\section{Procedimentos Metodológicos}

A seleção da temática origina-se nas experiências de vida dos pesquisadores, ou seja, as escolhas circunstanciais surgem a partir da aprendizagem instituída ao longo da vida, permitindo aos indivíduos a exploração espontânea dos acontecimentos e interações (Duarte \& Culver, 2014). Todos os autores atuaram como treinadores em categorias de base de modalidades coletivas e o primeiro autor ainda exerce essa 
função no futebol; todos têm vasta experiência com pesquisa qualitativa, no uso de entrevista semiestruturada e na análise de dados dessa procedência. Os autores têm vasta assim como relevante produção acadêmica em revistas indexadas (Bettega et al., 2015; González, Ibáñez, Feu \& Galatti, 2017; Galatti et al., 2016; Galatti, Bettega, Paes \& Scaglia, 2016).

Após a escolha da temática, organizado o desenho metodológico da pesquisa, que se classifica como um estudo empírico qualitativo. De forma específica é um estudo descritivo não estruturado, que analisa uma única amostra, um grupo de treinadores, portanto é um estudo de caso (Montero \& León, 2007). A compreensão do contexto investigado e dos dados obtidos foi realizada a partir da perspectiva sistêmica, em que o objeto se configura com base nos elementos de natureza e relações pertinentes às propriedades do sistema (Bertalanffy, 2013). A figura 1 representa de forma objetiva o percurso de vida dos pesquisadores, seus diferentes papéis e seus contextos de aprendizagem até a seleção da temática de estudo e imersão no campo de pesquisa.

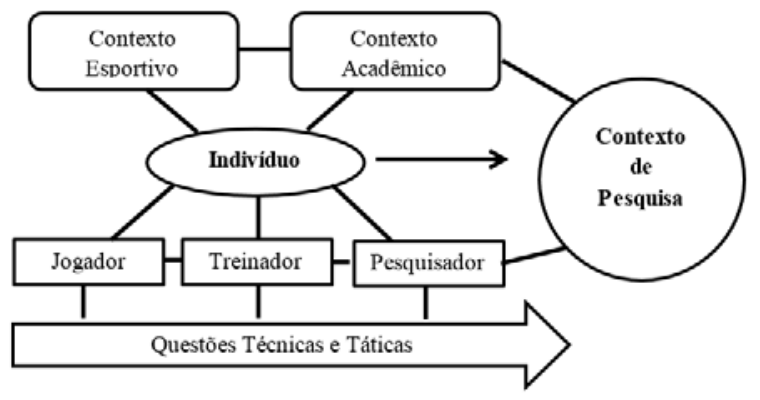

Figura 1. Trajetória de vida do investigador atéa escolha da temática de pesquisa.

\section{Participantes}

A seleção da amostra foi intencional, pois foi escolhido um clube. Além disso, a amostra é sistematizada, visto que as categorias escolhidas se deram a partir da sistematização das etapas de formação realizada no estudo de Bettega et al (2015). Participaram oito treinadores pertencentes às equipes de base de um clube de elite do futebol brasileiro. Além de fornecer atletas para as seleções de base e adulta, o clube é reconhecido no cenário nacional e internacional na formação de jogadores de futebol. No momento da escolha do clube a ser estudado em 2014, este se apresentava como primeiro no ranking de categorias de base no país (Sports21, 2014). A escolha dos treinadores das respectivas categorias faz referência com classificações encontradas em diferentes estudos da literatura consultada (Balyi, 2001; Bettega et al., 2015; Côté, 1999). Tal proposta se organiza nas seguintes etapas do processo de formação: Iniciação; Transição; Especialização, sendo que:

Iniciação: corresponde ao período inicial da prática esportiva (categorias sub 10 e sub 11), em que se busca desenvolver aspectos tático-técnicos básicos para atuação nas fases de ataque e defesa.

Transição: caracteriza-se pela fase (categorias sub 12, sub 13, sub 14) de aquisição e progressão do conhecimento do jogo e do comportamento tático-técnico.

Especialização: pressupõe ao momento de sustentação e aperfeiçoamento dos aspectos tático-técnicos do jogo (categorias sub 15, sub 16, sub 17).

\section{Instrumentos de coleta de dados}

O instrumento utilizado para a coleta dos dados foi a entrevista semiestruturada, que foi realizada no formato aberto, permitindo liberdade para o entrevistado responder os questionamentos realizados. A entrevista semiestruturada permite ao entrevistador a manutenção no foco da discussão, delineando os questionamentos com base em um roteiro preestabelecido, que geralmenteébaseado em temas geradores (Rathwell, Bloom \& Loughead, 2014).

A elaboração da entrevista obteve a participação de pesquisadores experientes na área da Pedagogia do Esporte, a partir de três temas geradores: o plano, o treino e o jogo. Enquanto que o plano contempla o momento de criação, o treino compreende o momento de construção e o jogo envolve o momento de reflexão. Para cada tema gerador, foram estabelecidos 10 subtemas, que versavam sobre as concepções do treinador referentes aos elementos táticos, técnicos, modelo de jogo, metodologia de treino e critérios de avaliação tático-técnica.

Como instrumento de pesquisa auxiliar, um diário de campo foi elaborado ao longo da coleta de dados, no qual o investigador contemplou anotações de algumas sessões de treinamento e jogos das equipes dos treinadores investigados, com ênfase na observação de conteúdos táticotécnicos (Cordes, Lamb, Lames, 2012). No diário foram relatados a organização e objetivos das atividades de treino, bem como acontecimentos relevantes relacionados ao comportamento do treinador e jogadores quanto ao treinamento tático-técnico.

\section{Procedimentos}

Com a realização do projeto piloto foi possível a organização dos temas geradores e definição das questões a serem abordadas. Desse modo, possibilitou a imersão no campo de pesquisa e operacionalização da coleta de dados, que ocorreu durante o período competitivo, no qual as equipes dos treinadores investigados disputavam o campeonato estadual de futebol. As entrevistas foram realizadas individualmente com cada treinador nas dependências do clube, utilizando-se de um gravador digital.

O investigador ficou quarenta dias acompanhando a rotina do clube, conversando com treinadores e outros profissionais e também registrando situações ocorridas no ambiente de treino através do diário de campo. Posteriormente o período de coleta dos dados, ocorreu à transcrição de todas as entrevistas e o envio aos treinadores para validação das declarações.

\section{Análise dos Dados}

Na análise das informações foram empregados os procedimentos de análise de conteúdo com base na proposta de Bardin (2011), estruturada em três etapas: (i) Pré-análise; (ii) Exploração do material; (iii) Tratamento e interpretação dos resultados. A validez interpretativa foi obtida a partir das análises complementares de dois investigadores com experiência acumulada em investigações desta natureza.

Todos os dados foram codificados por um analista e submetidos a um processo de análise de concordância intra-avaliador. O’Donoghue (2010) indica que o índice Kappa de Cohen (Cohen, 1960)é o estatístico válido para comprovar a concordância entre observadores para dados qualitativos. Os resultados de índice Kappa de Cohen intra-avaliador mostraram valores superiores à ,80, considerados por Landis e Koch (1977) como quase perfeitos.

\section{Resultados}

A sistematização dos resultados levou em consideração os três temas geradores das entrevistas: (i) Plano; (ii) Treino; (iii) Jogo. Além disso, o quadro 1 aponta a organização dos temas geradores relacionada com aspectos da teoria dos sistemas ecológicos, como: tempo, envolvimento pessoal em atividades, qualidade dos relacionamentos e cenário apropriado (Bronfrenbrenner, 1977; Côté, Strachan \& FraserThomas, 2008).

Quadro 1.

Organização dos temas geradores relacionada com os aspectos da teoria dos sistemas ecológicos.

\begin{tabular}{llll}
\hline Temas Tempo & $\begin{array}{c}\text { Envolvimento pessoal em } \\
\text { atividades }\end{array}$ & Qualidade das relações & Cenário apropriado \\
\hline Plano Antes & $\begin{array}{l}\text { Ação de criação } \\
\text { (das partes para o todo) }\end{array}$ & Treinador, comissão técnica, $\begin{array}{l}\text { Casa, próprio } \\
\text { clube. }\end{array}$ \\
\hline Treino Durante & $\begin{array}{l}\text { Ação de operacionalização (das Treinador, comissão técnica, } \\
\text { partes para o todo) }\end{array}$ & $\begin{array}{l}\text { jogadores. } \\
\text { jóprio clube }\end{array}$ \\
\hline \multirow{2}{*}{ Jogo Depois } & $\begin{array}{l}\text { Ação de reflexão (visualização } \\
\text { do todo integrado) }\end{array}$ & $\begin{array}{l}\text { Treinador, comissão técnica, } \\
\text { jogadores, torcida, } \\
\text { adversários, árbitros. }\end{array}$ & $\begin{array}{l}\text { Próprio clube, } \\
\text { clubes adversários. }\end{array}$ \\
\hline
\end{tabular}

O quadro 1 contempla os temas geradores alicerçados em aspectos da teoria dos sistemas ecológicos. Ou seja, o plano é apontado como o «antes», a ação de criação, que geralmente é elaborada pelo treinador e pela comissão técnica, em casa ou no próprio clube. O treino contempla 
o «durante», a ação de operacionalização, que geralmente é conduzida pelo treinador, comissão técnica e concretizada pelos jogadores no ambiente do clube. A temática de jogo refere-se ao «depois», a ação de reflexão, que geralmenteé realizada pelo treinador e comissão técnica a partir da interação estabelecida entre jogadores, adversários, árbitros na esfera do clube e em outros clubes. Ressalta-seque o processo édinâmico, logo, as ações são sucessivas e complementares, sendo que o plano pode ser realizado antes, durante e depois, bem como o treino e o jogo. Assim, o recorte dos resultados refere-se à visão inicial do investigador e procura identificar condições em que os treinadores relatam suas intervenções.

A figura 2 representa a organização dos temas geradores (plano, treino,jogo), das categorias (técnica, tática) e das subcategorias (técnica - técnica individual, gesto motor, forma analítica, execução de movimento, correção de movimento; tática - tática individual, tática setorial, tática coletiva, tomada de decisão, cognição). Salienta-se que os resultados são organizados a partir dos temas geradores e que a descrição das categorias e subcategorias acontece de forma contextual.

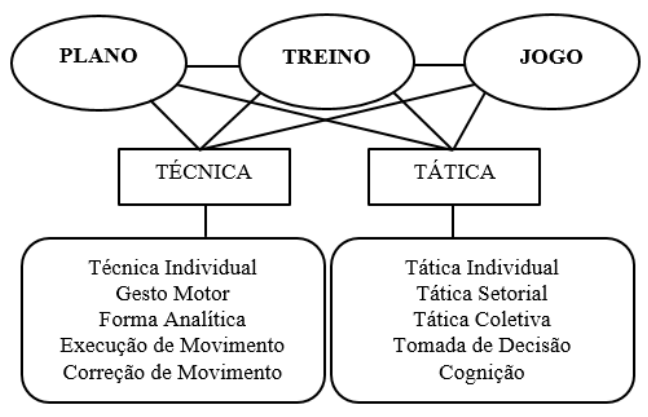

Figura 2. Organização dos temas geradores, categorias e subcategorias

No que diz respeito à temática de plano, os resultados indicam que os treinadores investigados não procuram distinguir o desenvolvimento da técnica de acordo com as etapas de formação que trabalham (iniciação, transição e especialização). De fato, todos os treinadores enfatizam o componente técnico aliado à tática, mas acreditam também no planejamento de conteúdos técnicos descontextualizados do jogo, sendo que somente um treinador enfatiza a tática, sem atribuir importância ao gesto motor.

Quanto ao plano de treinamento, os treinadores investigados relataram:

«Das partes técnicas do jogo, o passe, o cabeceio, a condução, o drible, o chute, são os princípios que envolvem o jogo, os fundamentos que envolvem o jogo [...]. Então esses são os mais importantes na categoria que eu atuo» (Treinador A).

«A gente trabalha o primeiro semestre, assim, não na totalidade do primeiro semestre, mais voltado para a técnica individual de cada um [...]» (Treinador B).

«Eu divido os momentos em parte ofensiva e defensiva, atacando principalmente a tática individual e a parte técnica do atleta [...]» (Treinador $C$ ).

«Eu acho que consegue trabalhar com todas as idades o mesmo conteúdo técnico/tático o que varia de uma idade para a outraéa ênfase que tu dás [...]» (Treinador D).

«Duas coisas que eu prezo muito são as tomadas de decisões, a parte cognitiva do atleta e a velocidade da execução do movimento, ter velocidade no jogo, velocidade que eu digo no jogo não é velocidade física do atleta, velocidade cognitiva na tomada de decisões [...]» (Treinador E).

«Todos os treinos são planejados para que o menino tome decisão e também para que ele tenha uma parte técnica boa, um gesto motor bom [...]» (Treinador F).

«Alguma coisa de tática individual, como postura corporal da marcação de um para um, o joelho flexionado, o centro de gravidade mais próximo do chão, evita a progressão do adversário [...]» (Treinador $G$ ).

«Uma equipe que consiga trabalhar muito bem a bola, que domi- ne bem os fundamentos para ser efetiva quando criar as chances [...]» (Treinador $H$ ).

Com relação a temática de treino, os relatos dos treinadores foram diversificados, embora sete valorizem a qualificação da técnica (gesto motor) como forma de auxílio ao trabalho tático. Enquanto que quatro treinadores relataram que procuram concentrar o desenvolvimento da fundamentação técnica do jogador no período inicial da temporada, outros treinadores destacaram que, em uma sessão de treino, primeiramente enfatizam aspectos técnicos para depois abordarem aspectos táticos, independentemente do período da temporada esportiva. Um treinador que enfatiza somente os aspectos táticos, embora seja observada a preocupação de alguns treinadores com a componente técnica contextualizada na esfera tática. Sobre a temática de treino, os treinadores comentaram:

«Agente trabalha exclusivamente a técnica básica de forma analítica, para ensinar os movimentos, para mostrar como éque funciona a execução de forma correta [...]» (Treinador A).

«Essa idade até os treze, quatorze anos a parte técnica tem que estar em evidência, os meninos têm que ter correção de movimentos [...]» (Treinador B).

«Acho que a forma analítica em uma forma sem oposição, de uma forma complexa na evolução daquele mesmo exercício de uma forma com oposição e depois sim contextualizada [...]» (Treinador C).

«Que a gente estabeleça ojogo pela posse, que a gente qualifique a parte técnica, passe, domínio, que são os fundamentos básicos para isso [...]» (Treinador D).

«Eu vou introduzindo a tática individual, a tática setorial e a tática coletiva vou complementando e dando uma sequência ao treinamento» (Treinador E).

«O primeiro treino é sempre com ênfase na questão técnica e cognitiva que eu vou usar no treino principal, que daí tem uma característica um pouco mais tática e coletiva [...]» (Treinador F).

«Contextualiza a parte do modelo de jogo com a questão analítica que nós vamos utilizar e também a gente procura utilizar com essa mesma situação com jogos de tomada de decisão [...]» (Treinador $G$ ).

«Fazer com que ele primeiro entenda o gesto que vai isola um pouquinho a atividade para ajudar ele na parte global também [...]» (Treinador $H$ ).

Na temática de treino algumas informações do diário de campo vêm para auxiliar e fortalecer os relatos realizados pelos treinadores:

«Segunda Atividade: jogadores em trios (duas filas) com troca de passes e movimentações para trocar de fila» (Treino: Treinador A).

«Primeira Atividade: Jogadores em filas passando por circuitos (escada de agilidade, saltando cones, mudando de direções) «(Treino: Treinador B).

«Segunda Atividade: Jogadores em um retângulo com quatro cones, sendo que ojogador tem que ir ao próximo cone, receber a bola escorada pelo companheiro e realizar um passe para o jogador que está no próximo cone» (Treino: Treinador $C$ ).

«Terceira Atividade: Trabalho de posse e quebra de pressão (6x6). A bola saí no goleiro e os jogadores (2 laterais, 2 zagueiros e 2 volantes) necessitam trocar 5 passes e assim tem como objetivo ultrapassar o meio campo com posse da bola» (Treino: Treinador D).

«Segunda Atividade: Jogo de $4 \times 2$ em círculo com dois toques, busca de manutenção da posse pelo ataque e interceptação de passe pela defesa» (Treino: Treinador E).

«Primeira Atividade: Dois jogadores, um de frente para o outro, sendo que a tarefa dos jogadores éconduzir a bola e entregar a mesma para o companheiro» (Treino: Treinador F).

«Terceira Atividade: Início com passe longo e cabeceio dos zagueiros, na sobra do cabeceio inicia uma situação de 3x2» (Treino: Treinador G).

«Segunda Atividade: Dois jogadores, um de frente para o outro, sendo que um atira a bola com a mão e o outro realiza o cabeceio» (Treino: Treinador H).

Diferentemente das temáticas anteriores, todos os treinadores investigados consideram o contexto tático do jogo nas suas avaliações na 
temática de jogo. Enquanto que alguns treinadores ressaltaram a preocupação com as escolhas individuais dos jogadores, outros treinadores demonstraram maior ênfase na tática coletiva. Alguns treinadores destacaram a análise da técnica na relação com a tática, do individual para o coletivo, ou seja, onde um gesto predispõe ou não um padrão tático.

De modo geral, os treinadores investigados relataram sobre a temática de jogo:

«A gente avalia sempre o coletivo, mas avalia também o individual, as escolhas que os meninos têm que ter dentro do campo [...]» (Treinador A).

O que acontece muito éque de ter se treinado muito uma coisa e se executar uma coisa diferente do que se treinou [...] eles tomam decisões por conta deles, o correto seria eles tomarem as decisões conforme se treina [...]» (Treinador B).

«Os dados que a gente colhe é muito da parte individual, mas não deixa da gente ter alguma parte coletiva, são vários dados de parte coletiva que tem, mas basicamente a parte mais individual [...]» (Treinador $C$ ).

«A gente deve estar fazendo uma avaliação constante, coletiva e individual, coletiva porque a gente tenta dentro de cada categoria estabelecer o seu modelo de jogo [...]» (Treinador D).

«Procuro passar em 5 fases nossas do jogo, que é a organização defensiva, organização ofensiva, as transições ofensivas e defensivas e as nossas bolas paradas ofensivas e defensivas [...]» (Treinador E).

«Eu brigo quando acontece alguma situação, quando o guri toma a decisão errada e é executada errada, se ele tomar a decisão certa e errar eu dou força para ele [...]» (Treinador F).

«Onde uma posição corporal não se adequo aquilo que o modelo de jogo está pedindo [...]» (Treinador $G$ ).

"Quando eu analiso um jogo eu não me preocupo tanto com a parte técnica, eu me preocupo mais com a parte coletiva, com a inteligência dele, comas tomadas de decisões que ele fez [...]» (Treinador H).

De maneira geral, os temas geradores de plano e treino foram visualizados das partes para o todo, ou seja, concebendo em parte a técnica individual (partes isoladas) para a tática coletiva (todo integrado) e o tema de jogo foi percebido com base no todo integrado, com ênfase na tática coletiva, conforme mostra a figura 3.

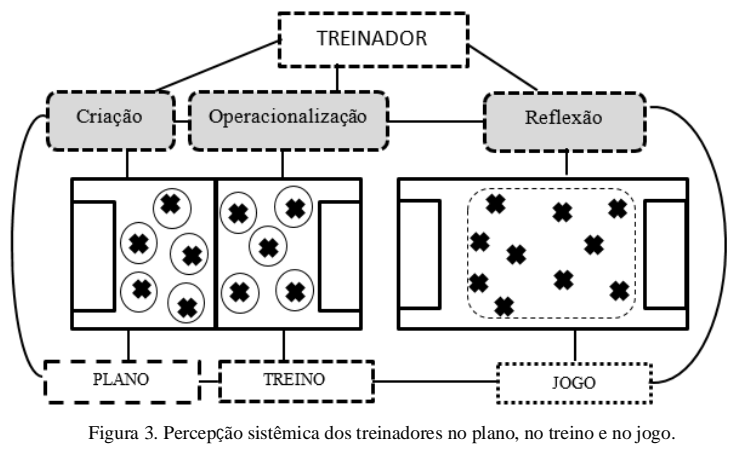

A figura 3 apresenta o treinador, os temas geradores (plano, treino e jogo) e as ações (criação, operacionalização e reflexão) com linhas pontilhadas, pois visualiza-se como relações e não objetos. Entretanto, os jogadores circulados individualmente são em algumas circunstâncias percebidos como objetos (plano e treino), enquanto na temática de jogo são vistos a partir das relações.

\section{Discussão}

Independentemente da etapa do processo de formação esportiva que atuam (iniciação, transição e especialização), sete treinadores investigados ressaltaram na temática do plano o domínio do gesto técnico como preponderante para a condição tática, ou seja, enfatizaram o trabalho técnico descontextualizado como importante para atuação do jogador no contexto tático do jogo. Esse olhar objetivo por parte dos treinadores investigados predispõe a busca de um «corpo» controlável, que atue em território conhecido (Cunha e Silva, 1999). Além disso, tal modelação corresponde a mínima variabilidade e adaptabilidade, atribuindo pouco significado às relações estabelecidas ou originadas no próprio jogo (Chow, Davids, Button, Renshaw, Shutleworth \& Uehara, 2009; Seifert, Button \& Davids, 2013).

A preocupação dos treinadores em qualificar o componente técnico como forma de auxílio ao componente tático tende a potencializar o gesto, mas descontextualiza a ocorrência simultânea e complementar entre técnica e tática. Para tanto, a ação do jogador decorre em um ambiente caótico, imprevisível enão linear, logo, o domínio de uma série de habilidades motoras não assegura a eficácia das ações. Assim, o planejamento deve priorizar o desenvolvimento da técnica em condições táticas que representem a variabilidade e aleatoriedade do jogo (Davids, Araújo, Shuttlerworth, 2005; Gréhaigne, Caty, Godbout, 2010).

Embora algumas observações realizadas e contempladas no diário de campo destaquem a realização de trabalhos com a técnica e a tática contextualizadas, alguns treinadores investigados planejam o desenvolvimento técnico desconexo dos aspectos táticos. Tais treinadores atribuem relevância ao aperfeiçoamento e correção do gesto técnico, justificando também pela etapa formativa que atuam (categorias iniciais). Contudo, o período de iniciação ao esporte e, nesse caso, ao futebol, deve congregar a diversidade de experiências e aprendizados, não se concentrando apenas na aquisição de gestos estereotipados, mas explorando a criatividade tática (Memmert, 2014).

As evidências referentes ao treino ressaltaram ainda que alguns treinadores conferem significância à qualificação e ao domínio da técnica como forma de aumentar o nível de eficácia das ações realizadas no jogo. Em contraponto, outros treinadores procuram desenvolver a técnica em jogos de tomada de decisão, ou seja, fomentam a busca de respostas motoras às situações do jogo. A potencialização da ação motora deve estimular os processos cognitivos, desenvolvendo habilidades perceptivas, de planejamento, antecipação, levando os jogadores a busca de decisões mais adequadas ao jogo (Broadbent, Causer, Williams \& Ford, 2014; Paterson, Kamp, Bressan \& Savelsbregh, 2013).

Apesar de a progressão do treinamento partindo do trabalho fragmentado da técnica para a contextualização tática seja a mais frequente entre os treinadores investigados, um deles destacou-se dos demais por enfatizar a progressão complexa em atividades contextualizadas, com ênfasenatática individual, setorial e coletiva. Ao acreditaremna linearidade no aprendizado dos jogadores para atuarem no jogo, os treinadores partem do princípio que a soma dos desempenhos individuais resulta um produto exato do coletivo, bem como que o desenvolvimento da técnica de forma analítica permita uma aplicação eficaz nas circunstâncias de jogo. Estudos atuais relacionados com o desempenho de jogo avançam os métodos analíticos tradicionais analisando os padrões de jogo a partir da evolução complexa de comportamentos, considerando situações dinâmicas do jogo, interações com companheiros e adversários e condições competitivas (Gréhaigne \& Godbout, 2014).

Um aspecto a destacar é que a progressão linear instituída pelos treinadores da técnica para a tática tem sido questionada, considerando a sequência acíclica e complexa do próprio jogo. Nesse sentido, Ibáñez, Feu, Antúnez e Cañadas (2013) propõem o modelo ondulatório, no qual as tarefas do treinamento são desenvolvidas de forma não linear e progressiva, alternando a priorização entre as fases de ataque e defesa, bem como entre a técnica e a tática. Assim, um treinador investigado apresentou uma percepção alinhada à compreensão sistêmica e não linear dos conteúdos tático-técnicos do futebol como apontam alguns estudos (Balague, Torrents, Hristovski, Davids \& Araújo, 2013; Davids, Araújo, Seifert \& Orth, 2015; Serra-Olivares \& Garcia-Rubio, 2017).

Os resultados referentes à temática de jogo mostraram que os treinadores enfatizam a avaliação no individual e no coletivo, atribuindo relação entre ambos. Ao considerarem que a ação do jogador em meio ao jogo é justificada pelas interações estabelecidas com o contexto, ou seja, o objeto édeterminado pelo sujeito(Hessen, 2000, p.51), tais treinadores ressaltaram a importância da análise com base nas escolhas realizadas pelos jogadores, considerando o «sujeito», suas interações com 
companheiros, adversários e com as condições de jogo. Desse modo, torna-se condizente os treinadores estimularem a autonomia dos atletas nas escolhas, criando um ambiente favorável para a tomada de decisão, aproximando as condições de treino com base nas disposições encontradas no jogo (Gréhaigne et al., 2010).

Todos treinadores destacaram a avaliação do jogo concentrada na técnica contextualizada com a tática, assim como no individual relacionado com o coletivo. Além de concordarem que a ação do jogador representa um processo tático-técnico singular que não separa a execução das razões para executar (Thelen \& Smith, 2006), esses treinadores analisam as movimentações dos jogadores com base na exploração das diversas possibilidades do jogo (Stolz \& Pill, 2014). A análise da tomada de decisão deve considerar o conhecimento já adquirido pelos jogadores, principalmente a partir das situações desenvolvidas no treinamento, mas ressalta-se que o processo se sustenta também nas informações do ambiente, tornando a ação complexa e adaptável as condições do contexto (Davids, Araújo, Villar, Renshaw \& Pinder, 2013;Araújo \& Davids, 2011). Desta forma, a relação da técnica com a tática, assim como do individual com o coletivo, torna-se relevantes nas apreciações desses treinadores, pois a ação do jogador condicionada por informações internas e externas não representa somente um gesto motor, mas cria significados para o âmbito tático coletivo do jogo.

A avaliação do jogo foi ressaltada por alguns treinadores também com base na organização coletiva da equipe. Nesse caso, a análise de padrões coletivos da equipe necessita reconhecer o comportamento dos jogadores como fontes de interação que constituem uma totalidade organizada, no qual se auto organiza as condições momentâneas (Lebed, 2013). O comportamento coletivo orienta-se a partir das regras de ação estabelecidas no modelo de jogo da equipe, da adaptação ao adversário eàs condições de jogo, assim, a análise coletiva conferida pelos treinadores torna-se relevante, pois irá dar pistas se os padrões de ação treinados estão ocorrendo nas situações de jogo (Malta \& Travassos, 2014). Para tal análise, Ballesta Castells et al (2015) destacam métodos atuais de avaliação, realizados por meio de GPS e que trazem maior fiabilidade nos dados, bem como possibilidade do cruzamento de diferentes variáveis (físicas, técnicas, táticas).

Demaneira geral, enquanto quena temática dejogo predominauma visão contextualizada entre a técnica e a tática, ou seja, os treinadores percebem o jogo na sua totalidade organizada, nas temáticas de plano e treino os resultados sinalizam perspectivas tecnicistas dos treinadores investigados, que visam à técnica também de forma fragmentada às condições táticas do jogo. Considerando que o planejamento, o treino e o jogo devem ocorrer de forma complementar e coerente, as evidências encontradas no estudo apontam queneste clube de referência na formação de atletas brasileiros a aprendizagem dos jogadores carece de um processo complexo, contínuo e que acompanhe as mudanças do indivíduo e a dinâmica do contexto (Light, 2008; Orozco, Pérez, Sierra, 2017).

Os relatos dos treinadores sobre como planejam e aplicam os treinamentos se aproximam, pois, obtêm preocupação com a melhora do gesto técnico descontextualizado para assim buscar ações táticas eficazes, embora em algumas situações os treinadores procurem relacionar tais conteúdos. No entanto, ao avaliarem os jogos de suas equipes, os treinadores privilegiam os aspectos táticos. Assim, há o questionamento se os aspectos táticos que compreendem o conteúdo predominante na avaliação do processo não deveriam também ser preponderantes ao planejar e conceber o treino. Além disso, destaca-se a relevância dos conhecimentos de Pedagogia do Esporte na construção do processo de ensino-treino do futebol, enquanto disciplina das Ciências do Esporte e, especificamente, no trato com modalidades coletivas, ela procura organizar, sistematizar, aplicar e avaliar procedimentos pedagógicos (Chow, 2013; Galatti, Reverdito, Scaglia, Paes \& Seoane, 2014).

\section{Considerações Finais}

A condução do percurso formativo do jogador de futebol sustentase, em grande parte, na estruturação do processo de ensino-treino. Nesse sentido, a condução do plano, do treino e do jogo deve ocorrer de forma complementar e com princípios pedagógicos delineados às condições estabelecidas no contexto de prática. No caso do presente estudo, a busca centrou-se na relação entre os aspectos táticos e técnicos explorados no processo de ensino-treino, a partir das concepções dos treinadores e nas observações de sessões de treinamento registradas no diário de campo.

As evidências encontradas com referência ao plano mostraram que sete dos treinadores investigados atribuem importância à qualificação técnica (gesto motor), apesar de também considerarem a componente tática. A perspectiva tecnicista também foi observada na temática de treino, porque os treinadores enfatizam o desenvolvimento de aspectos técnicos para depois progredir aos aspectos táticos, ou seja, parecem priorizar o trabalho com vistas à eficiência técnica como forma de auxiliar na resolução das questões táticas. Entretanto, os resultados referentes ao jogo evidenciaram que os treinadores procuram direcionar suas avaliações para a técnica contextualizada com a tática, no comportamento individual relacionado com o coletivo, reportando importância não para o gesto motor, mas para as escolhas realizadas pelos jogadores.

Em síntese, os resultados obtidos no estudo mostraram que nas temáticas de plano e treino sete dos treinadores investigados, mesmo trabalhando de forma contextualizada, ainda busca o desenvolvimento do aspecto técnico de forma fragmentada, concebendo o processo de ensino-treino na perspectiva que o objeto determina o sujeito. Entretanto, os resultados referentes à temática de jogo evidenciam que os treinadores consideram o contexto tático do jogo, não direcionando relevância para o aspecto técnico. Assim, constata-se que o pensamento objetivo estabelecendo relação de causa/efeito entre técnica e tática ainda predomina na construção do processo de ensino-treino nas categorias de base do futebol. Além disso, o pensamento subjetivo, com perspectivas reflexivas e complexas, concentra-se apenas nas avaliações dos jogos, daquilo que está construído, porém não ganha relevância na reconstrução constante do processo de ensino-treino.

A pesquisa obteve como fator limitante a falta de instrumentos de pesquisa para investigar as situações do treinamento e comportamentos do treinador e jogadores com maior profundidade, tal qual filmagem das sessões de treinamento e jogos. Vemos que este é ainda um limitador para investigações no esporte, já que é comum os clubes buscarem «proteger» informações de treino, dificultando o acesso de agentes externos (como pesquisadores) a registros do processo de treino. Desta forma, este estudo se centrou nas concepções dos treinadores, sendo recomendado a futuros estudos maior investimento em investigar o treino, dada a relevância desse momento para compreensão do processo de desenvolvimento do jovem jogador. Também são recomendados esforços em investigar a aprendizagem do treinador e dos jogadores.

\section{Agradecimentos}

Este estudo foi realizado com o apoio da Fundação de Amparo à Pesquisa do Estado de São Paulo (FAPESP), processo número 2015/ 01599-9. Este trabalho também foi parcialmente financiado pela ajuda dos Grupos de investigação (GR15122) da Junta de Extremadura (Consergería de Economía e Infreastructuras con la aportación de la Unión Europea) através dos FEDER.

\section{Referências}

Araújo, D., Fonseca, C., Davids, K., Garganta, J., Volossovicth, A., Brandão, R. \& Krebs, R. (2010). The role of ecological constraints of expertise development. Talent Development \& Excellence, 2(2), 165-179.

Araújo, D. \& Davids, K. (2011) What exactly is acquired during skill acquisition? Journal of Consciousness Studies, 18(3), 7-23.

Balague, N., Torrents, C., Hristovski, R. Davids, K. \& Araújo, D. (2013). Overview of complex systems in sport. Journal of Systems Science \& Complexity, 26(1), 4-13.

Ballesta Castells, C., García Romero, J., Fernández García, J.C. \& Alvero Cruz, J. R. (2015). Métodos actuales de análisis del partido de fútbol. Revista Internacional de Medicina y Ciencias de la Actividad Física y el Deporte, 15(60), 785-803. 
Balyi, I. (2001). Sport system building and long-term athlete development in british columbia. British Columbia: SportsMed.

Bardin, L. (2011). Análise de conteúdo. São Paulo: Edições 70.

Bertalanffy, L. (2013). Teoria geral dos sistemas: fundamentos, desenvolvimento e aplicações. Editora Vozes, $7^{a}$ Edição.

Bettega, O.B., Scaglia, A.J., Morato, M. \& Galatti, L.R. (2015). Formação de jogadores de futebol: princípios e pressupostos para composição de uma proposta pedagógica. Movimento, 21(3), 791-801.

Broadbent, D., Causer, J., Williams, M. \& Ford, P. (2014). Perceptualcognitive skill training and its transfer to expert performance in the field: future reserach directions. European Journal of Sport Science, 15(4), 322-331.

Bronfenbrenner, U. (1977). Toward na experimental ecology of human development. American Psychologist.

Cañadas, M., Parejo, I., Ibáñez, S., Garcia, J. \& Feu, S. (2009). Relationship between the pedagogical variables of coaching a mini-basketball team. Revista de Psicología del Deporte, 18(sup), 319-323.

Cañadas, M., Ibáñez, S. \& Leite, N. (2015). A novice coach’s planning of the technical and tactical content of youth basketball training: A case study. International Journal of Performance Analysis in Sport, 15(2), 572-587.

Chow, J.Y., Davids, K., Button, C., Renshaw, I., Shutleworth, R. \& Uehara, L. A. (2009). Nonlinear Pedagogy: implications for teaching games for understading (TGfU). Ottawa, Canadá: Physical Health Education Association.

Chow, J.Y., Davids, K., Button, C. \& Renshaw, I. (2013). The acquisition of movement skill in children through nonlinear pedagogy. In: Côte, J. \& Lidor, R. (Eds.). Conditions of Children's talent development in sport. Fitness Information Technology.

Chow, J. (2013). Nonlinear learning underpinning pedagogy: evidence, challenges, and implications. Quest, 65(4), 469-484.

Cohen, J.A. (1960). Coefficient of agreement for nominal scales. Educational and Psychological Measurement, 20, 37-46.

Cordes, O., Lamb, P. \& Lames, M. (2012). Concepts and methods for strategy building and tactical adherence: a case study in football. International Journal of Sports Science \& Coaching, 7(2), 241-254

Côté, J. (1999). The influence of the family in the development of talent in sport. The Sport Psychologist, 13, 395-417.

Côté; J., Strachan, L. \& Fraser-Thomas, J. (2008). Participation, personal development, performance through youth sport. In: Holt, N. Positive youth development through sport, Routledge.

Cunha e Silva, P. (1999). O lugar do corpo. Elementos para uma cartografia fractal. Lisboa: Instituto Piaget.

Davids, K. Araújo, D. \& Shuttlerworth, R. (2005). Applications of dynamical systems theory to football. In: Reilly, T., Cabri, J. \& Araújo, D. (Eds.). V Science and footbaal: the proceedings of the fifth world congresso on Science and football. London and New York. Rowtledge, 557-569.

Davids, K. Araújo, D., Villar, L., Renshaw, I. \& Pinder, R. (2013). An ecological dynamics approach to skill acquisition: implications for development of talent in sport. Talent Development \& Excellence, 5(1), 21-34.

Davids, K., Araújo, D., Seifert, L. \& Orth, D. (2015). Expert Performance in sport: an ecological dynamics perspective. In: Baker, J. \& Farrow, D. Routledge Handbook of Sport Expertise. New York: Routledge.

Duarte, T. \& Culver, D. (2014). Becoming a coach in developmental adaptive sailing: a lifelong learning perspective. Journal of Applied Sport Psychology, 26(4), 441-456.

Galatti, L. R., Reverdito, R., Scaglia, A.J., Paes. R.R. \& Seoane, A.M. (2014). Pedagogia do esporte: tensão na ciência e o ensino dos jogos esportivos coletivos. Revista da Educação Física/UEM, 25(1), 153162.

Galatti, L., Tozetto, A. V., Bettega, O. B., Rodrigues, H., Brasil, V. Z., Colett, C.,[...] Milistetd, M. (2016). Sport coaching as a profession in Brazil: na analysis of the coaching literature in Brazil from 20002015. International Sport Coaching Journal, 3(3),316-331.

Galatti, L. R, Scaglia, A. J, Bettega, O. B, Paes, R. R. (2016). Coaches' perceptions of youth players' development in a professional soccer club in Brazil: paradoxes between the game and those who play. Sports Coaching Review, 5(2): 174-185.
González, S., Ibáñez, S. J., Feu, S. \& Galatti, L. (2017). Programas de intervención para la enseñanza deportiva en el contexto escolar, PETB y PEAB: Estudio preliminar. Retos. Nuevas Tendencias em Educación Física, Deportes y Recreación, (31) 107-113.

Gréhaigne, J., Caty, D. \& Godbout, P. (2010). Modelling ball circulation in invasion team sports: a way to promote learning games through understanding. Physical Education and Sport Pedagogy, 15(3), 257270.

Gréhaigne, J. \& Godbout, P. (2014). Dynamic systems theory and team sport coaching. Quest, 66(1), 96-116.

Hessen, J. (2000). Teoria do conhecimento. São Paulo: Martins Fontes.

Ibáñez, S., Feu, S., Antúnez, A. \& Cañadas, M. (2013). Avances y desafios em la formación de los entrenadores de desportes colectivos. In: Nascimento, J., Ramos, V. \& Tavares, F. (Org.). Jogos Desportivos: formação e investigação. Editora Tribo da Ilha, Florianópolis.

Landis, J. R., \& Koch, G. G. (1977). The measurement of observer agreement for categorical data. Biometrics, 33, 159-174.

Lebed, F. (2013) Complex systems in team sports. In: Mcgarry, T. \& O'donoghue, P. Sampaio, J. Routledge Handbook of Sport Performance Analysis. London: Routledge.

Lee, M. C., Chow, J. Y., Komar, J., Tan, C. W. \& Button, C. (2014). Nonlinear Pedagogy: An Effective Approach to Cater for Individual Differences in Learning a Sports Skill. Plos ONE, 9(8), 1-13.

Light, R. (2008). Complex learning theory: its epistemology and its assumptions about learning: implications for physical education. Journal of Teaching in Physical Education, 27(1),21-37.

Malta, P. Travassos, B. (2014). Caracterização da transição defesa-ataque de uma equipe de futebol. Motricidade, 10(1), 27-37.

Memmert, D. (2014). Tactical creativity in team sports. Research in Physical Education, Sport and Health, 3(1), 13-18.

Montero, I. \& León, O. (2007). A guide for naming research studies in Psychology. International Journal of Clinical and Health Psychology, 7(3), 847-862.

Orozco, A. M., Pérez, A. A. \& Sierra, F. S. (2017). Estudio descriptivo sobre el entrenador de fútbol sala prebenjamín en La Rioja: perfil, motivaciones, cualidades y dicicultades. Retos. Nuevas Tendencias em Educación Física, Deportes y Recreación, (31) 164-170.

O’Donoghue, P. (2010). Research Methods for Sports Performance Analysis. Abingdon, UK: Routledge.

Paterson, G. Kamp, J. V., Bressan, E. \& Savelsbergh, G. (2013). The effects of perception-action coupling on perceptual decision-making in a self-paced far aiming task. International Journal Sport Psychology, 43(3), 1-18.

Raiola, G. \& D'Isanto, T. (2015). Assessment of periodization training in soccer. Journal of Human Sport \& Exercise, 11(1), 267-278.

Rathwell, S., Bloom, G \& Loughead, T. (2014). Head coaches'perceptions on the roles, selection, and development of the assistant coach. International Sport Coaching Journal, (1), 5-16.

Santos, F., Côrte-Real, N., Regueiras, L., Dias, C. \& Fonseca,A. (2016). O papel do treinador do desenvolvimento positivo de jovens através do desporto: do que sabemos ao que precisamos saber. Revista Iberoamericana de Psicología del Ejercicio y el Deporte, 11(2), 289-296.

Santos, F. J., Lopes, H. M., Rodrigues, J. J. (2016). Relação entre a percepção de jovens futebolistas e o comportamento de instrução e dos atletas em competição. Revista Iberoamericana de Psicología del Ejercicio y el Deporte, 11(1), 59-68.

Seifert, L., Button, C. \& Davids, K. (2013). Key properties of expert movement systems in sport: an ecological dynamics perspective. Sports Medicine, 43(3), 167-178.

Serra-Olivares, J. \& Garcia-Rubio, J. (2017). La problemática táctica, clave en el diseño representativo de tareas desde el enfoque de la pedagogía no lineal aplicada al deporte. Retos. Nuevas Tendencias em Educación Física, Deportes y Recreación, (32), xxx-xxx.

Sports 21. (2014) Ranking da base. http://www.sports21.com.br/ranking-base.asp. Acesso: 15/9/2014.

Stolz, S. \& Pill, S. (2014). Teaching games and sport for understanding: exploring and reconsidering its relevance in physical education. European Physical Education Review, 20(1), 36-71.

Thelen, E. \& Smith, L. (2006). Dynamic systems theories. In: Damon, R. \& Lerner, R. Handbook of Child Psycology, 6 Edition, 2006. 